\title{
Yoğun bakım ünitemizdeki (YBÜ) perkütan trakeotomi pratiğimiz
}

\author{
Tolga Totoz ${ }^{1}$, Hacer Şebnem Türk², Pınar Sayın², Oya Ünsal², Surhan Çınar ${ }^{3}$, Sibel Oba²
}

\begin{abstract}
ÖZET:
Yoğun bakım ünitemizdeki (YBÜ) perkütan trakeotomi pratiğimiz

Giriş ve Amaç: Perkütan trakeotomi(PT) uygulaması, kısa sürede yatak başında uygulanabilme ve daha az kanama gibi avantajları, ayrıca uzamış yapay solunum gereksinimi, "weaning"in kolaylaştırılması, acil hava yolu sağlanması gibi endikasyonlarla yoğun bakım ünitelerinde sıklıkla tercih edilir. Cerrahi trakeostomiye alternatif yöntemdir. Bu çalışmada ki amacımız YBÜ'mizde son 4 yılda açılan trakeotomileri uygulama günü, uygulama zamanı ve uygulama sonrası komplikasyonları açısından analiz etmektir.

Yöntem: 01.01.2007 ve 31.12.2010 tarihleri arasında YBÜ'mizde tedavi edilen 603 olgudan perkutan trakeotomi uygulanan 132 olgu analiz edildi. Perkütan trakeotomi uygulaması griggs tekniğiyle bir ekip tarafından gerçekleştirildi. Demografik verileri, uygulama günü, toplam mekanik ventilasyon günü, uygulama zamanı ve uygulama sonrası komplikasyonları kayıt edildi.

Bulgular: Son 4 yılda YBÜ'mizde takip ve tedavi edilen 603 olgudan 132'sine perkütan trakeotomi pratiği bu periotta uygulandı. Kadın-Erkek oranı $62 / 70$, olguların yaş ortalaması $58.65 \pm 17.22$ yıl, olguların ortalama hastanede yatış süresi $38.77 \pm 28.74$ gün, trakeotomi pratiği öncesi ortalama entübasyon süresi $8.20 \pm 5.44$ gün, toplam mekanik ventilasyon süresi $26.85 \pm 21.70$ gün ve ortalama operasyon uygulama zamanı $6.1 \pm 2.1$ dakikaydı. 86 olgu komorbiditelerinden dolayı YBÜ'mizde öldü. 46 olgu ilgili servislere transfer edildi. Toplam komplikasyonlar (8 olgu) kayıt edildi.

Sonuç: YBÜ'de uzamış mekanik ventilasyon intiyacı, weaning'i kolaylaştırması, acil hava yolu sağlaması gibi endikasyonlarla uygulanan peruktan trakeotomi basit, düşük komplikasyon oranına sahip ve minimal girişimsel uygulamadır.
\end{abstract}

Anahtar kelimeler: Yoğun bakım, trakeotomi, komplikasyon

\section{ABSTRACT:}

Percutaneous tracheotomy practices in our intensive care unit (ICU)

Introduction and Objective: Percutaneous tracheotomy practice is usually preferred at ICU for the advantages of able to be applied in a short time and at the bedside and it causes less bleeding. It is the alternative of surgical tracheotomy. The aim of this study is to analyze tracheotomies that were opened in our ICU in last 4 years, within the terms of practice day, practicing duration and post practice complications.

Method: 132 percutaneous tracheotomy practiced cases of 603 cases that were treated in our reanimation unit between 01.01.2007 and 31.12.2010 were analyzed. Percutaneous tracheotomy practices were conducted via Griggs technique by a team. Demographic information, practice day, total mechanical ventilation days, practicing duration and post practice complications were recorded. Findings: 603 cases were followed up and treated in ICU in last 4 years. 132 Percutaneous tracheotomy practices were applied in this period. It is figured out that women-man ratio was $62 / 70$, the mean of age of the cases was $58.65 \pm 17.22$ years, the mean hospitalization time of cases was $38.77 \pm 28.74$ days, the mean intubation time before tracheotomy practice was $8.20 \pm 5.44$ days, total mechanical ventilation days $26.85 \pm 21.70$ and the mean practicing duration of operation was $6.1 \pm 2.1$ minutes. 86 cases were deceased due to the comorbidities at ICU. 46 cases were transferred to the related services. Total complication (8 cases) were encountered.

Result: Percutaneous tracheotomy which was practiced for indications such as need for mechanical ventilation for long time, easing weaning, providing urgent airway in ICU; is simple, has low complication ratio and is minimally invasive practice.

Key words: Intensive care, tracheotomy, complication

Ş.E.E.A.H. Tıp Bülteni 2013;47(1):11-15
'Uzman Doktor, Trabzon Ahi Evren Göğüs Kalp ve Damar Cerrahisi Eğitim ve Araştırma Hastanesi, Trabzon-Türkiye

Uzman Doktor, Şişli Etfal Eğitim ve Araştırma Hastanesi, İstanbul-Türkiye

${ }^{3}$ Doçent Doktor, Şişli Etfal Eğitim ve Araştırma Hastanesi, İstanbul-Türkiye

Yazışma Adresi / Address reprint requests to: Uzman Doktor Hacer Sebnem Türk, Șişli Etfal Eğitim ve Araştırma Hastanesi Anesteziyoloji ve Reanimasyon Kliniği, istanbul-Türkiye

Telefon / Phone: +90-532-443-2544

E-posta / E-mail:

hacersebnem@yahoo.com.tr

Geliş tarihi / Date of receipt: 23 Ağustos 2012 / August 23, 2012

Kabul tarihi / Date of acceptance: 27 Ağustos 2012 / August 27, 2012 


\section{GíRiş}

Yüzyıllardır uygulanan trakeostomi; yoğun bakım dalında ilerlemeler, değişen endikasyonlar, özellikle de yatak başı perkütan tekniklerin gelişmesiyle günümüzde daha da sık kullanılmaktadır. Yirmibirinci yüzyılda ise; perkütan trakeotominin hangi hastalarda, hangi yöntemle, ne zaman açılacağı tartışılmakta ve bu tekniğin hasta sonuçlarını nasıl değiştirdiği araştırılmaktadır.Yoğun bakım ünitelerinde endotrakeal entübasyon uygulanan ve uzun süre mekanik ventilatöre bağlı kalacağı öngörülen hastalara trakeotomi açılması tavsiye edilmektedir $(1,2)$. Uzamış endotrakeal entübasyonun larengeal hasar, vokal kord paralizisi, glottik ve subglottik stenoz, infeksiyon, trakeal hasar (trakeomalazi, trakeal dilatasyon ve trakeal stenoz) gibi komplikasyonları vardır (3). Uzamış endotrakeal entübasyona bağlı gelişebilecek komplikasyonları azaltmak amacıyla gerçekleştirilen trakeotomi ile larengeal hasarı azaltmak, hemşirelik bakımını ve solunum yollarının aspirasyonunu kolaylaştırmak, güvenli havayolu sağlayarak hastanın mobilizasyonunu artırmak, hastanın yoğun bakımdan transferini ve ağızdan beslenmeyi kolaylaştırmak, hasta konforunu artırmak, konuşmanın erkenden geri dönmesine yardımcı olmak, ve havayolu rezistansını azaltmak amaçlanmaktadır. Bu avantajlarına rağmen trakeotomi invaziv bir girişimdir ve girişimle ilgili bazı komplikasyonlar gelişebilmekte$\operatorname{dir}(4)$.

Trakeostominin eski Mısır döneminden (M.Ö. 3500 yılından) beri yapıldığı belirtilmektedir, fakat ilk elektif trakeostominin M.Ö. 100. yılda; kuzeybatı Anadolu topraklarında kurulmuş olan Bithynia krallığında yapıldığına dair kaynaklar bulunmaktadır. Trakeostomi yüzyıllardır yabancı cisim, travma veya infeksiyonlara bağlı üst hava yolu tıkanıklıklarında hayat kurtarıcı olmuştur $(5,6)$.

Standart cerrahi trakeostomi ilk kez Jackson tarafından $1909^{\prime}$ da, ilk modern perkütan trakeotomi ise Shelden ve ark. tarafından $1955^{\prime}$ de tarif edilmiştir $(7,8)$. Günümüze kadar birçok perkütan trakeotomi yöntemi tarif edilmiş olmasına rağmen en sık kullanılan teknikler Ciaglia ve ark. tarafından 1985 'te tarif edilen perkütan dilatasyonel trakeotomi tekniği ile Griggs ve ark. tarafından 1990 'da tarif edilen perkü- tan gide wire dilatasyonel trakeotomi tekniğidir $(9,10)$. Perkütan trakeotominin basit, komplikasyon hızı düşük, ameliyathane ortamı gerektirmeyen ve hasta yatağında kısa sürede uygulanabilen bir yöntem olması gibi avantajları vardır $(11,12)$.

Bu çalışmada, yoğun bakım ünitemizde Griggs tekniği ile açılan perkütan trakeotomilerin açılma zamanı, işlem süresi ve erken komplikasyonları açısından retrospektif olarak sunulması amaçlandı.

\section{GEREÇ VE YÖNTEM}

Çalışmamızda 2007-2010 yılları arasında Griggs yöntemi ile perkütan trakeostomi açılan, 62'si kadın, 70'i erkek 132 olgu, retrospektif olarak değerlendirildi. Hemostatik bozukluğu olmayan (trombosit sayısı 50000 (mm3)-1 üstünde olan, aktive parsiyel tromboplastin zamanı ve protombin zamanı kontrol değerinin 1.5 katından az olan), trakea ve boyun yapısı normal olan (guatr, geçirilmiş boyun cerrahisi, boyunda yumuşak doku enfeksiyonu olmayan) hastalara işlem uygulandı. Bütün trakeostomiler elektif şartlarda deneyimli uzman veya uzman eşliğinde en az 2.5 yılını tamamlamış anestezi asistanı tarafından gerçekleştirildi. İşlem öncesi hastaların yaş, cinsiyet ve entübasyon süresi kaydedildi. Hastalar işlem süresince elektrokardiyografi, pulse oksimetri, solunum sonu karbondioksit basıncı ile invaziv/non invaziv arter basıncı ile monitorize edildi. İşlem "Percutaneous tracheostomy kit" (Portex, Hythe, Kent, İngiltere) ile gerçekleştirildi. İşlem sırasında fiberoptik bronkoskop kullanılmadı. Hastalara işlem öncesi fentanil $1 \mu \mathrm{gg}$ kg-1, propofol $3 \mathrm{mg} \mathrm{kg-1}$ ve rokuronyum $0.1 \mathrm{mg}$ kg-1 intravenöz verildikten sonra \%100 oksijen ile pozitif basınçlı mekanik ventilasyon (MV) uygulandı. Hasta düz olarak sırt üstü pozisyonda yatırıldıktan sonra omuz altı desteği ile baş ekstansiyona getirildi. Hastanın baş kısmında duran yardımcı tarafından endotrakeal tüp kafı indirilerek tüp vokal kordların altına kadar çekildikten sonra tüp kafı tekrar şişirildi. İşlem için steril giyinildi. Boyun bölgesi antiseptik solüsyonla silindikten sonra delikli yeşil ile örtüldü. Trakeal kartilajın birinci ve ikinci veya ikinci ve üçüncü aralığı palpe edilerek işlem yapılacak bölgeye \%2 lidokain (2-3 ml) ile lokal anestezi uygulandı. Lokal anestezi sonrası cilt bölgesine bistüri yardımıy- 
la vertikal bir insizyon $(8-10 \mathrm{~mm})$ yapılarak $3 \mathrm{ml}$ serum fizyolojik çekilmiş ucunda 14G iğne bulunan enjektör yardımı ile belirlenen bölgeden aspirasyon yapılarak trakea lümenine girildi. Enjektöre hava aspire edildiğinde enjektör iğneden ayrılarak içinden geçirilen kılavuz tel trakea lümenine yerleştirildi. Kılavuz telin üzerinden geçirilen $8 \mathrm{~F}$ dilatatör yardımıyla bölge genişletildi. Dilatatör çıkarılarak forseps yardımıyla cilt, cilt altı ve trakea genişletildikten sonra $7.5,8$ veya 8,5 numara trakeotomi tüpü trakeaya yerleştirildi. Kılavuz tel çekildi. Trakeotomi tüp kafı şişirilerek tüp içi aspirasyon yapıldıktan sonra hasta ventilatöre bağlandı. Trakeotomi tüp çevresi temizlendikten sonra steril spanç sarıldı. Solunum sesleri dinlendikten sonra hastalara yatağında akciğer grafisi çektirildi.

Hastalarda gelişen erken komplikasyonlar (minör kanama, cerrahi kanama, subkutan amfizem, pnömotoraks, yanlış pasaj, hipoksi ve mortalite) kaydedildi. İşlem sonrası stoma çevresine sarılan spançlar ile kanamanın kısa sürede durmaması ve/veya trakeotomi tüpü içinden aspirasyonla kan gelmesi minör kanama olarak değerlendirildi. Baskılı kompreslere rağmen stomadan ve/veya aspirasyonla trakea içinden gelen kanamanın devam etmesi cerrahi kanama olarak tanımlandı. Ayrıca; işlem için harcanan süre (iğne girişinden trakeostomi kanülünün yerleştirilmesine kadar geçen süre) kaydedildi. Mekanik ventilasyon süresi (gün), toplam yatış süresi (gün), hastaneden çıkış durumu (sağlıklı/trakeotomili/ölüm) kaydedildi.

İstatistiksel analiz, SPSS 10.0 programında yapıldı. Veriler sayı $(n)$ veya ortalama \pm standart sapma (SS) olarak sunuldu.

\section{BULGULAR}

60 olguya kalıcı yapay solunum gereksinimi, 72 olguya ise uzayan yapay solunum ihtiyacı sebebiyle trakeotomi açılmıştır,

Hastaların demografik verileri, entübasyon süresi, işlem süresi, toplam $M V$ süresi ve $\mathrm{YB}^{\prime}$ da yatış süresi ile hastaların hastaneden çıkış durumları Tablo 1'de gösterilmiştir.

Olguların hastaneden çıkış durumlarına bakıldığında 16 olgu dekanüle edilerek, 30 olgu kalıcı tra-
Tablo 1: Demografik veriler. Griggs $(n=132)$

\begin{tabular}{ll}
\hline Kadın-Erkek oranı & $62 / 70$ \\
Olguların yaş ortalaması & $58.65 \pm 17.22$ yıl \\
$\begin{array}{l}\text { Olguların ortalama hastanede yatış } \\
\quad \text { süresi }\end{array}$ & $38.77 \pm 28.74$ gün \\
$\begin{array}{l}\text { Trakeotomi pratiği öncesi ortalama } \\
\quad \text { entübasyon süresi }\end{array}$ & $8.20 \pm 5.44$ gün \\
Toplam mekanik ventilasyon & $26.85> \pm 21.70$ gün \\
Ortalama operasyon uygulama zamanı & $6.1 \pm 2.1$ dakika
\end{tabular}

Tablo 2: İşleme bağlı komplikasyonlar. Sıklık n 8 (\%6)

\begin{tabular}{ll}
\hline Pnömotoraks & 3 \\
Stoma çevresinden erken kanama & 2 \\
Subkutan amfizem & 1 \\
Orta dereceli kanama & 1 \\
Abondan kanama & 1
\end{tabular}

keotomi kanülü ile yaşamına devam etmektedir. 86 olgu ise yoğun bakım ünitemizde yandaş hastalıkları nedeniyle kaybedilmiştir.

İşleme bağlı erken komplikasyonlar tablo 2'de gösterilmiştir. İşlem sırasında gelişen toplam erken komplikasyon oranı \%6 olarak tespit edildi. ìlk yıl 1 olguda 8 'inci. günde trombositopeni nedeniyle orta dereceli kanama saptandı. 1 olguda ise $9^{\prime}$ uncu günde trakeotomi kanülü değiştirilirken yanlış yerleşim sonrası subkutan amfizem gelişti ve tekrar kanüle edildi. İkinci yıl 2 olguda pnömotoraks, 2 olguda stoma çevresinden erken dönemde kanama ve 1 olguda da 30'uncu günden sonra trakeotomi içerisinden abondan kanama görüldü. Anjio ile bronşial arter kanaması olduğu tespit edilerek ligasyon uygulandı. Üçüncü yıl her hangi bir komplikasyon ile karşılaşılmadı. Dördüncü yıl ise sadece 1 olguda pnömotoraks gelişti. Hiçbir hastada işleme bağlı ciddi hipoksi ve mortalite gelişmedi.

\section{TARTIŞMA}

Son yıllarda tıp alanındaki teknolojik gelişmeler sonucunda bazı cerrahi girişimler yerini perkütan tekniklere bırakmıştır. Daha az invaziv olan bu teknikler doku travmasını ve komplikasyon oranını azaltmaktadır. Günümüzde perkütan trakeotomi yoğun bakımlarda yaygın olarak kullanılmaktadır (12). 
Angel LF ve arkadaşlarının yaptığı çalışmada 260 olguya cerrahi trakeostomi, 272 olguya ise peruktan trakeotomi uygulanmış; operasyon zamanları ve kanama yönünden istatistiksel anlamlı fark bulunmamıştır. Cerrahi trakeostomi de toplam 54 komplikasyon ile karşılaşılmış, perkütan trakeotomi de ise bu rakam 18'de kalmıştır. Cerrahi trakeostomi de 19 olguda, perkütan trakeotomi de sadece 10 olguda enfeksiyonla karşılaşılmıştır $(13,14)$. Bizim çalışmamızda da toplam 132 olgudan 8'inde komplikasyon gelişmiştir.

Perkütan tekniklerde en sık görülen komplikasyonlar; transfüzyon veya cerrahi gerektirmeyen kanama, subkutan amfizem, kanülün trakea dışına yerleştirilmesi, trakea arka duvarında yaralanma, kısa süreli hipoksi ve stoma infeksiyonudur. Kearney ve arkadaşlarının 827 olguluk perkütan trakeotomi serilerinde perioperatif mortalite $\% 0,6$ ve yine perioperatif komplikasyon oranı \%6, erken postoperatif komplikasyon oranı \%5 olarak belirtilmiştir (15). Halum SL ve arkadaşlarının yaptığı çok merkezli çalışmada da intraoperatif erken ve geç dönem komplikasyonları da çalışmamıza benzer bulunmuş olup erken dönem ( $<1$ hafta) komplikasyonu \%5,6 ve geç dönem komplikasyonu \%7,1 olarak bulmuşlardır $(16,17)$. Bizim çalışmamızda da 6'sı erken dönem(stoma çevresinden kanama,pnömotoraks ve cilt altı amfizem), 2'si geç dönem olmak üzere komplikasyonumuz olmuştur.

Kanama ile ilgili olarak değişik sonuçları olan çalışmalar bulunmaktadır (11). Stomadan, sızıntı şeklinde olan kan kaybının 50-100 ml olduğu gösterilmiştir. Minör kanamaların, uzamış işlemlerde görüldüğü ve kompresyonla kontrol altına alındığı, major kanamalarda ligasyon gerektiği bildirilmiştir (11).

Griggs tekniğinde pnömotoraks oluşması \%0-3 arasında görülmekle birlikte, oran genelde düşüktür. Çalışmamızda, işleme bağlı olarak 3 (\%2) olguda pnömotoraks gelişmiştir. Perkütan trakeostomide deneyimin önemi, birçok yazar tarafından literatürde belirtilmiştir $(18,19)$. Petros ve Engelmann (20), tüm zamanlardaki komplikasyon oranını \%11, akut komplikasyon oranını ilk 2 yılda \%18, son 2 yılda \%6 bulmuş ve bunu deneyime bağlamışlardır. İlk 2 yıl 7 komplikasyonumuz var iken son iki yıl sadece 1 komplikasyonumuzun olması deneyimin önemini göstermektedir.

Griffiths J. Ve arkadaşlarının yaptığı meta-analiz çalışmasında vardıkları sonuca göre yoğun bakım hastalarına trakeotomi erken dönemde uygulanmalıdır. 406 hastayı içeren 5 çalışma incelendiğinde yoğun bakımda kalış süresi, yardımcı ventilasyon ihtiyacı, erken trakeotomi açılan hastalarda azalmaktadır (21). Rumbak MJ ve arkadaşlarının yaptığı çalışmada ise erken trakeotomi açılan olgular ile uzamış entübe olgular karşılaştırıldığında ölüm, pnömoni görülme oranı, yoğun bakımda kalış süresi, mekanik ventilasyon ihtiyacı, sedasyon ihtiyacı oranlarının erken trakeotomi açılan olgular da istatistiksel olarak diğer gruba göre kısa bulmuşlardır (22). Bizde olgularımıza ortalama 8.gün de trakeotomi açtık.

Çalışmamızda; erken komplikasyon olarak minör kanama $(\% 1,5)$ ve pnömotoraks $(\% 2)$ tespit edildi. İşlem süresi ortalama 6,21 dk idi. Ancak bu süre hem uzman hem de asistanlar için genel ortalamayı yansıtmakta olup uzman ve asistanlar için işlem süreleri ayrı ayrı belirlenemedi. Bronkoskop kullanılmamasına rağmen komplikasyon oranımızın (\%6) literatürlerle uyumlu olması işlemlerin deneyimli uzman veya uzman denetiminde yapılmasının sonucu olabilir.

Sonuç olarak; Griggs tekniği ile perkütan trakeotomi açılmasının yatak başında kısa sürede uygulanan, düşük komplikasyon oranına sahip bir yöntem olduğu ve cerrahi trakeostomiye alternatif olarak güvenle uygulanabileceği kanaatine varıldı.

\section{KAYNAKLAR}

1. Plummer AL, Gracey DR. Consensus conference on artificial airways in patients receiving mechanical ventilation. Chest 1989;96:178-80.

2. Marsh HM, Gillespie DJ, Baumgartner AE. Timing of tracheostomy in the critically ill patients. Chest 1989;96:190-3.

3. Whited RE. A prospective study of laryngotracheal sequelae in term intubation. Laryngoscope 1984;94:367-77.

4. Friedman $Y$. Indications, timing, techniques and complications of tracheostomy in the critically ill patient. Curr Opin Crit Care 1996;2:47-53. 
5. Borman J, Davidson JT. A history of tracheostomy: Si spiritim ducit vivit. Br J Anaesth 1963;35:388-90.

6. Frost EAM. Tracing the tracheostomy. Ann Otol 1976;85:618-24.

7. Jackson C. Tracheostomy. Laryngoscope 1909;19:285-90.

8. Shelden $\mathrm{CH}$, Pudenz RH, Freshwater DB, et al. New method for tracheotomy. J Neurosurgical 1955;12:428-31.

9. Ciaglia P, Firshing $R$, Syniec C. Elective percutaneous dilational tracheostomy: a new simple bedside procedure. Chest 1985;87:715-9.

10. Griggs WM, Wortley LIG, Gilligan JE, et al. A simple percutaneous tracheostomy technique. Surg Gynecol Obstet 1990; 170: 543-5.

11. Anon JM, Gomez V, Escuela P, et al. Percutaneous tracheostomy: comparison of Ciaglia and Griggs techniques. Crit Care 2000;4:124-8.

12. Rao BK, Pande R, Sharma SC, et al. Percutaneous tracheostomy. Annals of Cardiac Anaesthesia 2003;6:19-26.

13. Angel LF, Simpson CB: Comparison of surgical and percutaneous dilational tracheostomy. Clin Chest Med 2003; 24:423-429.

14. Oliver ER, Gist A, Gillespie MB. Percutaneous versus surgical tracheotomy: an updated meta-analysis. Laryngoscope. 2007 Sep;117(9):1570-5.

15. Kearney PA, Griffen MM, Ochoa JB, Boulanger BR, Tseui $B J$, Mentzer RM Jr: A single-center 8-year experience with percutaneous dilatational tracheostomy. Ann Surg 2000; 231:701-9.

16. Halum SL, Ting JY, Plowman EK, Belafsky PC, Harbarger CF, Postma GN, Pitman MJ, LaMonica D, Moscatello A, Khosla $S$, Cauley CE, Maronian NC, Melki S, Wick C, Sinacori JT, White Z, Younes A, Ekbom DC, Sardesai MG, Merati AL. A multi-institutional analysis of tracheotomy complications. Laryngoscope. 2012 Jan;122(1):38-45. doi: 10.1002/lary.22364.
17. Luna Azoulay B, Béquignon A, Babin E, Moreau S. Preliminary results of percutaneous tracheotomies. Ann Otolaryngol Chir Cervicofac. 2009 Jun;126(3):125-32.

18. Wang MB, Berke GS, Ward PH, Calcaterra TC, Watts D. Early experience with percutaneous dilatational tracheostomy. Laryngoscope 1992;102:157-62.

19. Hazard PB, Garrett HE Jr, Adams JW, Robbins ET, Aguillard RN. Bedside percutaneous tracheostomy: experience with 55 elective procedures. Ann Thorac Surg 1988;46:63-7.

20. Petros S, Engelmann L. Percutaneous dilatational tracheostomy in a medical ICU. Intens. Care Med 1997;23:630-4.

21. Griffiths J, Barber VS, Morgan L, Young JD: Systematic review and meta-analysis of studies of the timing of tracheostomy in adult patients undergoing artificial ventilation. BMJ 2005;330: 1243.

22. Rumbak MJ, Newton M, Truncale T, Schwartz SW, Adams JW, Hazard PB: A prospective, randomized study comparing early percutaneous dilational tracheotomy to prolonged translaryngeal intubation (delayed tracheotomy) in critically ill medical patients. Crit Care Med 2004;32:1689-94.

23. Birbiçer H, Doruk N, Yapıcı D, ve ark. "PercuTwist" yöntemi ile peruktan trakeostomi deneyimimiz. GKD Anest Yoğ Bak Dern Derg 2006;12(2):80-3. 